\title{
Editorial: ISPIM Bangkok
}

\section{Stoyan Tanev, Editor-in-Chief and Gregory Sandstrom, Managing Editor}

Welcome to the August issue of the Technology Innovation Management Review. This month features papers from the ISPIM Connects Bangkok Conference Partnering for an Innovation Community, held on March 1-4, 2020. The publication of this special issue was driven by Dr. Xavier Parisot and Dr. Thierry Isckia, Professors at Bangkok University. An additional paper by another regular ISPIM participant rounds out the list of contributions. The special issue is a wonderful example of ongoing cooperation with the leaders of the ISPIM society in promoting innovation management research.

The issue opens with Karl Joachim Breunig and Tale Skjølsvik's paper, "Understanding the StrategyInnovation Link in an Era of Disruptions". Their conceptual research focuses on links between strategy and innovation in leading management journals. In the background are the organizational capabilities and environmental turbulence of companies aiming to capitalize on innovation. The authors note, "Most contemporary organizations face challenges related to achieving sustainability and advantages in periods of market change" (p. 9). Their findings are relevant for managers seeking to develop strategies "while increasing their innovative abilities and capacities" (p. 10), and business leaders aiming to navigate through an era of disruptive technological development.

Christina öberg follows with "Open Marketing: Conceptualizing external parties' strategic marketing activities". Öberg's paper provides a typology including four types of roles and role keepers involved in marketing. She discusses how or whether "open marketing" changes the traditional view of marketing, based on two case studies, of a joint venture partnership between an IT company and a marketing agency, and a web-based community for product development built on recycled materials. In addition to addressing marketing role temporality, the author points out that "control over marketing is ... increasingly exchanged for parties that act based on their own understandings", where "marketing roles may also be shared among several different parties" (p. 24). The paper proposes a balance between control over internal company resources and external party interests to participate, formally or informally, in marketing a company's products or services.

The next paper provides "A Triadic Actor View of Value Co-creation in Business Incubation" by Ronald Beckett and John Dalrymple. The 'triadic view' goes beyond the traditional incubator-client value creation arrangements, to include other service ecosystem stakeholders. The authors take an 'actor-oriented' approach by highlighting four different cases of incubators and other service entities that support startups' development. This involves co-working spaces, knowledge-sharing, innovation infrastructure, financing, and technology assets in value co-creation initiatives. The results show that "Incubator actors need to actively engage with investors and demonstrate the benefits of incubation realized" (p. 35). The authors insist that "an actor-centric view may offer greater appreciation of startup incubation dynamics than a business model view" (p. 36).

Hiromi S. Nagane and Koichi Sumikura present the final paper: "Which Factors Influence a Company's Evaluation of the Contribution of Basic Research to Innovation?" The authors make an empirical analysis of "how individuals in companies evaluate the contributions of basic research by universities and public research institutes to industry" (p. 39), in order to assess the 'health' or 'sickness' of innovation in Japan. The paper inquires into the factors that influence a company's evaluation of the contribution of basic research to innovation, regarding pharmaceutical companies and biotech startups. The study's results reveal that "inventors with extended research careers tended to assign low values to public research contributions, while inventors with a Ph.D. tended to assign high values" (p. 48). They conclude that "if companies lack talent that can adequately discern and evaluate academic research, engagement with external basic research outcome stagnates" (p. 51).

The TIM Review currently has a Call for Papers on the website for a special edition on "Aligning Multiple Stakeholder Value Propositions". For future issues, we invite general submissions of articles on technology entrepreneurship, innovation management, and other topics relevant to launching and scaling technology companies, and solving practical problems in emerging domains. Please contact us with potential article ideas and submissions, or proposals for future special issues.

Stoyan Tanev, Editor-in-Chief Gregory Sandstrom, Managing Editor

Citation: Tanev, S. and Sandstrom, G. 2020. Technology

Innovation Management Review, 10(8): 3.

http://doi.org/10.22215/timreview/1381
(cc)BY 